\title{
A case study on processes in team building and performance improvement at Government Health Centers in Rajasthan, India
}

\section{Bhaskar Purohit}

Indian Institute of Public Health - Gandhinagar, Sardar Patel Institute Campus, Ahmedabad, Gujarat, India

Address for the Correspondence:

Mr. Bhaskar Purohit, Indian Institute of Public Health - Gandhinagar, Sardar Patel Institute Campus, Drive in Road, Thaltej, Ahmedabad - 380 054, Gujarat, India. E-mail: bpurohit@iiphg.org

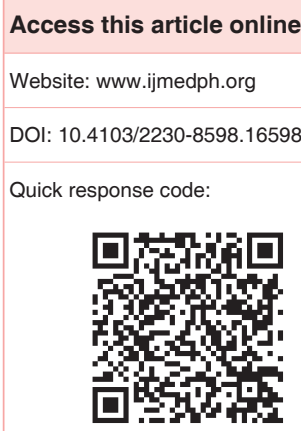

Introduction: Public healthcare system in India suffers from poor performance mainly due to the severe shortage and high absenteeism of healthcare providers. The performance is further affected due to low productivity and competencies of the already existing healthcare providers. While management training (with a special focus on human resource issues) to address the shortage to healthcare providers has gained some importance in recent past, there has been a very limited focus on how to use the exiting workforce effectively. With this backdrop, training health providers in issues pertaining to team effectiveness becomes very crucial. The case study discusses some of the dimensions of team building, as well as processes involved in performance improvement including problem identification, prioritization, and problem-solving process as demonstrated by health system improvement teams (HSIT's). Materials and Methods: HSIT's have been constituted and are functional at 238 secondary level facilities in Rajasthani. The case writer interacted with five HSIT's from two districts in Rajasthan. We were able to speak to about four to five members from each team for all the five facilities. The information for the case was gathered in two ways. The first was use of an instrument on team building that was given to each member of the team to gauge their individual perception about various team building aspects. The second was with the help of group discussions that were done with all the team members for each all the five teams. All those who were present and willing to be part of the discussion were given instruments and were included in group discussions. As this was an exploratory case study, the sample size was small and, therefore, the findings from group discussion and instruments have been presented together without any quantification of the data. Results: The findings of the case study indicate moderate team empowerment. While HSIT's were clear about their respective roles and tasks, they could not establish a link between their own goals and team goals. Limited autonomy is available with very less autonomy to implement solutions that involve money or recruiting people. Most of the team members reported, high support received from senior teams for solving the problems. As far as the team performance improvement processes are concerned, teams reported good collaboration in form of improved and effective communication, and joint problem solving. Most of the team members reported that the decisions are taken based on the consensus of the whole group. Such teams rely on their intuitive power than any management tools for identifying and prioritizing problems. Conclusion: It can be said that performance improvement through HSIT's is really a unique and innovative concept. There are some positive team building indicators reflected by HSIT's that have resulted in better work reflected through regular and productive meetings; people having a chance to raise concerns in the meetings; improved communication channels and improvement in infrastructure. However, there are some weaknesses within the processes, as well as some team related aspects. More research and focus should be channeled to study the importance of processes and team building factors in performance improvement of individuals, teams, and the organizations and its link to increased effectiveness.

Key words: Health system improvement teams, process improvement, team building

Rajasthan is the largest state in India by area. It is located in central part of Rajasthan and is bordered by Gujarat State in Southwest and MP to south east. It has a population of 68.6 million with literacy rate of $61 \%$.

This is an open access article distributed under the terms of the Creative Commons AttributionNonCommercial-ShareAlike 3.0 License, which allows others to remix, tweak, and build upon the work non-commercially, as long as the author is credited and the new creations are licensed under the identical terms.

For reprints contact: reprints@medknow.com

How to cite this article: Purohit B. A case study on processes in team building and performance improvement at Government Health Centers in Rajasthan, India. Int J Med Public Health 2015;5:372-7. 


\section{INTRODUCTION}

Healthcare workers today work in a highly complex health systems. Such complexities are only likely to accelerate in India where health system face increasing trends of communicable and noncommunicable diseases, demographic shifts, and dearth of competent health providers, especially in rural areas. The solutions to public health problems are not straight forward and are often complex, that require the health systems to think beyond routine solutions. Finding out new ways to deal with challenges becomes all the way more important due to severe shortage of health workforce in rural areas ${ }^{[1]}$ and huge migration of Indian doctors to other countries. ${ }^{[2]}$ According to research studies the Indian Healthcare Services suffer from low quality and poor access which further make people utilize more private services and increase their out of pocket expenditures. ${ }^{[3]}$ Despite significant efforts to raise government resources toward health sector, the health indicators remain very low. While it is true that part of the health results are not achieved because of poor human resource (HR) composition, availability, and distribution within and across the states and country, what is also true is that the already existing limited health providers are not able to produce satisfactory results mainly due to lowered team effectiveness.

While HR issues have gained some importance in recent past, such efforts have been limited to address the severe shortage of providers. Very limited attention has been paid to some of the crucial ways to use the existing workforce effectively. ${ }^{[4]}$ For instance, challenges surrounding HR development are being increasingly recognized by the policy makers in order to strengthen and improve HR capacities to mainly meet healthcare delivery requirements. However, there has been a very limited understanding and research on the challenges and issues of the HR for health from the viewpoint of increasing team effectiveness with nearly zero focus on crucial processes of team building. Since public health is multi-disciplinary, the solutions have to be multi-disciplinary, with a strong focus on processes of team building. Research from other countries indicates that higher teamwork has been reported to be significantly associated with nurses' job satisfaction, lower burnout and a plan to stay longer in a job and a strong association between teamwork and autonomy. ${ }^{[5]}$

It is well-known that healthcare providers do not have adequate managerial skills and competencies to be effective within their teams and organizations. ${ }^{[6]}$ Studies from three Indian states indicate that it may be very difficult under national rural health mission to achieve its desired targets mainly due to managerial and HR constraints at the state level. ${ }^{[7]}$ It is unfortunate that the health systems, researchers, and policy makers lack any sensitivity to team building issues.

With this backdrop, there are two aspects discussed in the case: The team related aspects and the processes involved in performance improvement including problem identification, prioritization, and problem solving process as reflected by the Health System
Improvement Teams (HSIT) ${ }^{\mathrm{ii}}$.

\section{MATERIALS AND METHODS}

The main aim of the project is to improve the quality of healthcare with the help of special teams called the HSIT's. For this purpose, the project has a multi-pronged approach called performance improvement. The case study looks at the crucial processes of performance improvement that included problem identification, problem prioritization, and problem-solving process at the facility level by HSIT's with a special focus on team building processes.

HSIT's have been constituted and are functional at 238 secondary level facilities in Rajasthan ${ }^{\text {iii }}$. The case writer interacted with five HSIT's from two districts in Rajasthan. We were able to speak to about four to five members from each team for all the five facilities.

iDetails about HSIT and Project:

The approach of performance improvement includes the following actions: Action 1: Inputs like civil work, equipment, pharmaceuticals and training.

Action 2: Performance assessment and problem solving at facility level through HSIT's.

Action 3: Monitoring and Evaluation system.

Action 4: Analysis of client's feedback.

In addition to this, Project has clearly defined the following roles and functions of HSIT's:

Different roles under HSIT:

- Define roles and responsibilities for all team members for smooth functioning of the facility.

- Set and share performance targets with the staff.

- Analyze hospital statistics and evaluate hospital performance before monthly HSIT meeting.

- Crosscheck a sample of hospital data for its validity.

- Facilitate active involvement of all members of the team in improving hospital system by assigning independent responsibilities so that each staff member feels a sense of ownership towards the institution.

Composition of District Hospital level to be as follows:

- Principal Medical Officer (PMO) - Chairman.

- Deputy Superintendent.

- Pathologist.

- Heads of different clinical department.

- Nursing superintendent.

- Stores officer.

- Class IV worker.

Composition of HSIT's at CHC level:

- Medical officer in charge - Chairman.

- JS-Surgery/SMO - Member secretary.

- All Junior Surgeons and Medical officers.

- Nursing staff.

- Class IV worker.

Function of HSIT in the following way:

- Planning and preparation of meetings.

- Conducting the meetings.

- Drafting the minutes of the meeting.

- Circulating the minutes.

iiiRajasthan is the largest state in India by area. It is located in central part of Rajasthan and is bordered by Gujarat State in Southwest and MP to South East. It has a population of 68.6 million with literacy rate of $61 \%$. 
The information for the case was gathered in two ways. The first was the use of an instrument on team building that was given to each member of the team to gauge their individual perception about various team building aspects. The second was with the help of group discussions that were done with all the team members for each all the five teams. All those who were present and willing to be part of the discussion were given instruments and were included in group discussions. None of the team member present at the facility during the case writers visit refused to be participates in the study. As this was an exploratory case study, the sample size was small and, therefore, the findings from group discussion and instruments have been presented together without any quantification of the data.

\section{RESULTS AND DISCUSSION}

The findings have been divided into two parts:

a. Team building aspects.

b. Processes involved in performance improvement.

\section{Team building aspects}

The two main dimensions of team building are: Team empowerment and team function.

These two dimensions have several additional aspects, which are discussed below.

\section{Team empowerment}

The aspects of team empowerment are: Task clarity, autonomy, support, and accountability.

\section{Task clarity}

This may be defined as how well the team members are clear about the overall tasks given to each member individually and the collective task, which has to be performed by the team. This is the first and the most important step to team empowerment because unless the team members know what is expected of them, they cannot be effective in their roles and cannot use the resources within the team and the organization effectively. ${ }^{[8]}$

All the HSIT's reported that they have a well-defined team goal, which is patient satisfaction through quality improvement. However, there did not seem a clear link between individual goals and goals of the team, and goal of the project. For example, some of the team members shared that while they were clear about their respective roles within the team and also the goal of the team/organization, they could not establish a link between their own goals and team goals. A few respondents shared that sometimes the tasks given to them under HSIT are not very clear to them that leads to task ambiguity.

\section{At one of the facilities, team leader/facility in-charge shared}

"The tasks given to members are not very clear. Sometimes in my absence, it is not clear who would take the role of supervising the team and taking the overall responsibility. Since, team members are not clear about it, they find ways and excuses not to take responsibility for that particular task." The example he gave was: "When I was not around, there was a problem with the inverter, which was making a strange sound for 2 days. However, none of the team members bothered to look at the problem as they were not clear if it was their job or not. They also did not do it, because it would increase their work and accountability. Due to the inverter problem, the hospital work suffered to a great deal."

\section{Autonomy}

Autonomy is both, using and giving freedom to individuals to plan and act in one's own sphere. Higher autonomy may result in mutual respect and is likely to result in willingness to take on responsibility, individual initiative, better succession planning, and accountability. ${ }^{[8}$

The team members reported that they have enough freedom to decide the way they want to work. For example, team members reported that they are given high freedom in identifying and reporting the problems concerning their facility. However, not much freedom is available when it comes to implementing the problemsolving process that often requires taking decisions related to money or HR problems.

One of the team members said: "We face frequent problems either related to procurement of equipment or their repairs. Sometimes, even a small repair of equipment requires approval from health system improvement committees (HSIC) which affects the overall work at the facility."

At another facility, the team leader reported the following: "The biggest areas where we lack autonomy are the decisions involving recruitment or need for manpower. Due to a severe lack of manpower at his facility, the drug dispenser is playing multiple roles of ward boy, works at the below poverty line counter and distributing the slips."

Lack of autonomy mainly pertaining to the matters relating to money was reflected in the ineffective delegation by the team heads. A Lack of autonomy relating to decisions involving money is also reflected in frequent referrals being made to teams at next level called HSIC's for approvals and sanctions regarding things required at the facility.

\section{Support}

Support is defined as needed help to an individual that facilitates him to achieve individual, teams, and organizational goals. ${ }^{[8]}$

All the teams reported very high support received from HSIC for most of the problems raised in HSIT meetings. However, a few members also reported that they have failed to receive timely support related to infrastructure and particularly manpower.

System support is provided by ensuring that teams have competent people to handle their respective tasks. Again, while system support is available by providing competent people, the system fails to provide an adequate number of staff which affects quality and effectiveness.

"We face electricity problem here. The solution is very simple and 
requires a few thousand rupees, but the problem has been continuing for over a few months despite raising it constantly in HSIT minutes."

All the visited facilities reported a high support received from HSIC. "The project has helped for the construction of operation rooms, labor room, X-ray rooms, and laboratories, timely supply of drugs, procurement and repairs of equipment at facilities. The satisfaction level of all the team members and doctors have also increased, and inflow of patients due to better facilities has increased at our facility."

\section{Team functioning}

Team functioning may be defined as working together collaboratively to achieve team goals. It means that collective action, ideas, and working would always bring greater results than what the best individual within the groups can get. $^{[8]}$

\section{Collaboration}

Collaboration means giving help to, and asking for help from others. It means working together (individuals and groups) to solve problems and team spirit. ${ }^{[8]}$

The HSIT's reported good collaboration in the form of improved and effective communication and solving the problems jointly. Improved communication is constantly reflected in regular monthly meetings of HSIT's that are mandatorily attended by the head of the team at the facility.

Productive outcome of such meetings are the minutes that clearly state the agenda for the meeting, the main discussion about the meeting, any problems that HSIT's face in implementing the action plan to improve quality and what kind of support is needed from the project for effective addressing the problems raised in such minutes. Another positive aspect of such meetings is the joint decisions of the team on prioritizing the problems or on finding solutions to such problems.

One of the HSIT's reported: "Formation and effective implementation of such teams have improved the communication among team members. All team members are willing to help each other and do their work with commitment. HSIT meetings are also helpful for us to plan our agenda for the coming month and help us look at how we are progressing."

\section{Confrontation}

Confrontation can be defined as facing rather than shying away from problems. It also implies a deeper analysis of interpersonal problems. All this involves taking up challenges. ${ }^{[8]}$

Such teams, in general, reported that they lack innovations to generate alternative ways to solve the problem. The main reason given for this was a lack of finances which prevents to try out new ideas.

However, most of the team members reported that they have no problem in taking tough decisions as such decisions are taken based on the consensus of the whole group. This is what one of the facility in-charge had reported: "The team members generally, have no difficulty in raising their concerns or the concerns relating to their department. There are also no personal differences among team members because regular HSIT meetings provide a platform to raise and discuss any issues, concerns or problems team members have."

\section{Health system improvement teams process of improving performance: Problem identification, prioritizing and problem-solving process}

\section{Process of delegation and division of work}

A preliminary step, much before teams reach the stage of problem solving is the process of formation of teams and distribution of roles and responsibilities under such teams. In real sense, the concept of delegation means that the senior persons like district project coordinator (DPC) or members from HSIC and team leader/facility incharge from HSIT's need to evolve along with other team members the areas in which they would like to use their team members competencies, and ways in which they could use their discretion to make the desired impact. ${ }^{[8]}$

Most of the teams reported that senior members including the team leader do not shift work and responsibilities to their junior members about something, which the senior members do not like to do. This is what one of the respondents said "All team members share the responsibilities equally."

The delegation work under HSIT is done in the following way. Usually, the most senior member (position wise) of the facility takes the role of the delegator and to supervise the team. It was observed at all the visited facilities that the most senior member, in terms of the hierarchy has taken the role of team leader/facility in-charge. It was reported by all the team leaders that the delegation of different roles was carefully done after taking into consideration individual competencies and interests [Figure 1].

Another positive indicator of the effective delegation was reflected when the majority of the respondents shared that the delegation of work and responsibilities in no way has led to an overload of work.

\section{The process of problem identification}

The process of problem identification begins with HSIT meeting where different issues pertaining to the facility are raised. This meeting is generally attended by all the team members. Staff members from the facility not part of the team are also encouraged to attend the meeting and raise any concerns that they have in their respective departments. Such meetings are held monthly which are mandatory for the team leader/facility in-charge to attend. In order to keep an account of problems raised in the meeting, DPC's are also encouraged also attend the meetings.

The process of problem identification in such meetings is more intuitive and lacks the use of any management tool or scientific approach to identify problems. For example, when asked about the process problem identification, members reported that they simply identify problems that they think are important. The main criterion for categorizing a problem to be important or not so important is mainly the experience and perception of members about the 


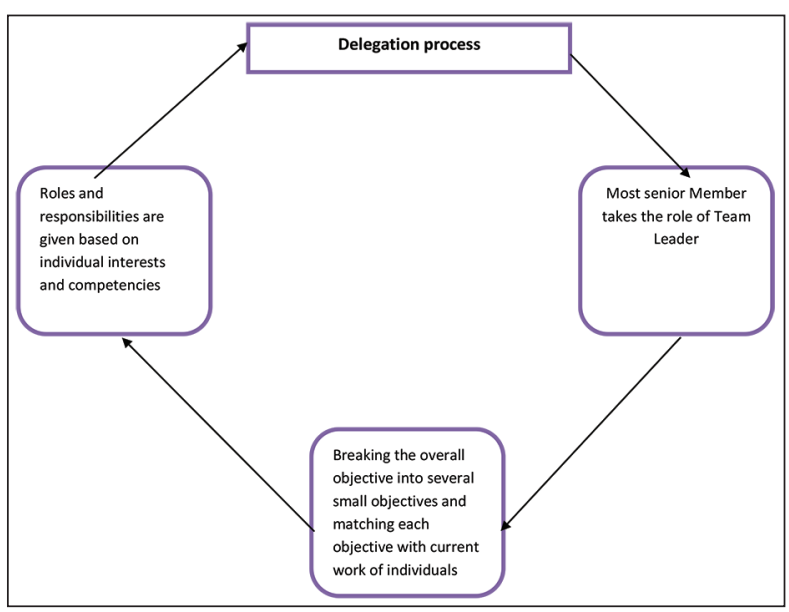

Figure 1: The process of delegation and division of work

problem and what other others members collectively think about the problem. The rationalization of such decisions is mainly based on their experiences and is sometimes not consolidated or backed by the use of hospital data. Therefore, most of the visited facilities were not sure about the use of Diagnostic-Tree (D-tree) to identify facility related problems and seemed completely ignorant about the Problem or D-tree ${ }^{\text {iv }}$.

Also, most of the problems reflected in HSIT meetings revolve around finance, equipment, construction or civil work, manpower needs or repairs. Therefore, minutes of the meeting generally reflect such problems. The problems raised in the meetings do not reflect a careful use and analysis of hospital activity format (HAF) data to identify problems. However, teams try to identify problems jointly which indicates good teamwork.

\section{The process of prioritizing the problems}

The problems raised in the meeting are prioritized more intuitively than using a systematic approach like using the diagnostic or problem tree to see causes of the causes and then ranking the problem in order of importance to the facility. Once the major problems are identified (generally on the basis of what most feel), opinion is taken from various members about if they think the problem is important and requires immediate action or not. Generally what majority people say is identified as the main problem.

Looking deeper into the process we realize that sometimes the problems are prioritized based on what majority people think is important. While this can be one way to prioritize problems, there is an inherent flaw in this approach. Prioritizing problems solely on the basis of what majority think may mean that people who are in the minority may not have had a chance to communicate their point of view. It may also mean that while people in the minority may have stronger and valid points, their viewpoints are not taken into final consideration for the reason that majority people in the team

${ }^{\text {iv }} \mathrm{D}$-Tree or diagnostic tree is a management tool used to logically identify root cause of a problem. It is also used to identify main problems or frame problem statements within HSIT's. All the HSIT members have been trained to use D-Tree for problem identification. do not think like them. This approach, rather than strengthening the team may create a feeling of dissatisfaction among the people who are in the minority and may also divide the group into subgroups. For example, members who believe and support hierarchy would invariably support what the team leader/facility in-charge says and the decision taken by in-charge may become the final word.

\section{Communicating the problems to the concerned people and regular follow-up}

Proper minutes are maintained that serve as a way to document the problems faced by the team. These minutes are signed by the head of the team. After circulation, the minutes are given to DPC's who act as links between HSIT and HSIC. The concerns raised in such minutes are further discussed by DPC with HSIC. If the issue can be resolved at HSIC level, necessary measures are taken otherwise problems raised in the minutes are referred to Health System Resource Teams (HSRT).

One of the positive things about this approach is that everyone's consent is taken and then the minutes are finalized. The minutes also serve as a formal record and proof for any discussion that take place during the HSIT meeting and no one can deny or give an excuse of being ignorant as all the members sign leaving no scope for ambiguity.

Another advantage of maintaining the minutes that came out from the discussion was that such minutes help in planning the activities for the facility. For example, one of the facility in-charge shared that such minutes help them to plan the availability of hospital staff for the coming period as the hospital staff discusses a tentative plan for the coming month.

\section{CONCLUSIONS AND RECOMMENDATIONS}

\section{Autonomy and delegation as tools for empowerment}

As discussed already, autonomy and delegation have worked in some favor of teams. Some of the areas where autonomy has been provided include the way teams want to delegate work amongst its members, freedom to raise any problem they think affects the performance of the team and facility. However, HSIT's have very less autonomy related to financial matters and matters relating to recruitment of HR. Lack of power and dearth of staff at the facility was reported as the biggest reason for dissatisfaction amongst all the teams. Therefore, more autonomy must be provided to HSIT team members, especially in matters pertaining to finance, procurement, and repairs of equipment and issues relating to recruitment HR. Our findings also indicate that delegation is of no use in the absence of autonomy. Therefore, team members must be helped to use their power effectively through effective delegation. While it has been already discussed that the team leaders assign the tasks based on individual competencies and interests, such team members lack the autonomy. Therefore, senior persons like DPC's or members 
from HSIC and team leader/facility in-charge from HSIT's need to provide more autonomy to its members in order to make the delegation more effective.

\section{Training all health system improvement teams in problem identification and problem-solving}

As discussed in the previous section, HSIT's identify and prioritize health center problems based on their intuition without much use of data generated through HAF. The data available through HAF is robust and includes details on important aspects such as the accessibility of services, clinical services, diagnostic services, manpower availability, and hospital efficiency. However, it is not being used effectively. Therefore, it is very important for all the HSIT members to understand clearly the process of problem identification with the help of using D-tree. Use of such a technique would help them analyze the problems in a better and more logical way. While deciding on the problems to analyze causes of the causes and to find solutions to such problems, it is very important for the team members to use the hospital data for generating the problems statements and use them as a base for framing problem statement under D-tree.

\section{Developing mechanisms to monitor technical, managerial and team skills/competence}

While the project has a robust mechanisms to monitor the performance of HSIT's based on data and indicators such as accessibility of services, clinical services, diagnostic services, manpower availability, and hospital efficiency data available through an HMIS system, such data does not reflect some of the processes and competencies involved in achieving such outputs. Therefore, efforts must be made to develop some sort of monitoring system that can measure the individual and team processes that lead to the achievement of such outputs. To measure individuals and teams progress on human and managerial skills, project must design some sort of self-assessment instruments that not only helps the project, but also the individuals and teams to develop their competencies to increase team effectiveness. Such instruments may also be used to design training programs requiring special attention in the technical/clinical areas, managerial areas, and team related aspects.

\section{Emphasis on team building}

The focus of the project is on the achievement of results without any focus on team building and behavioral aspects that contribute to teamwork. Therefore, importance must be given to team building aspects. As discussed in the problem identification part, the group must consciously understand the process of making a decision in a team.

\section{Developing a system of reward and recognition and linking it to performance}

Team building and individual development is a gradual process. Therefore, it needs to be monitored, encouraged, and reinforced. Rather than waiting for and rewarding the people for big achievements, small processes, and achievements should be reinforced positively and rewarded in monetary and nonmonetary terms. This can lead to higher satisfaction and motivation amongst the team members. Such reward or recognitions should be based solely on performance and not on favoritism.

\section{Acknowledgment}

I would like to thank senior project staff including project director, deputy project director for allowing us to carry this work. I would also like to thank the other staff of the project who provided us with the background information about the project. We are also grateful to participants of the study for their time. The author would like to thank late Prof. Pareek, who allowed the author to use his framework, instruments and definitions for various aspects on the team included in the present study.

\section{Financial support and sponsorship}

Nil.

\section{Conflicts of interest}

There are no conflicts of interest.

\section{REFERENCES}

1. Rao M, Rao KD, Kumar AK, Chatterjee M, Sundararaman T. Human resources for health in India. Lancet 2011;377:587-98.

2. Government of India. Task Force for Planning on Human Resources in Health Sector. Planning Commission, Government of India; 2006.

3. Selvaraj S, Karan A. Deepening health insecurity in India: Evidence from National sample survey since 1980. Econ Polit Wkly 2009;64:55-60.

4. Government of India. National Rural Health Mission (2005-2012) Mission Document. New Delhi: MoHFW; 2005.

5. Rafferty AM, Ball J, Aiken LH. Are teamwork and professional autonomy compatible, and do they result in improved hospital care? Qual Health Care 2001;10 Suppl 2:ii32-7.

6. Kumpusalo E, Virjo I, Mattila K, Halila H. Managerial skills of principal physicians assessed by their colleagues. A lesson from Finland. J Health Organ Manag 2003;17:457-62.

7. Bajpai N, Sachs JD, Dholakia RH. Improving Access and Efficiency in Public Health Services: Mid-term Evaluation of India's National Rural Health Mission. New Delhi: SAGE Publications India Pvt Ltd.; 2010.

8. Pareek U. Understanding Organizational Behaviour. $2^{\text {nd }}$ ed. New Delhi: Oxford University Press; 2007. 